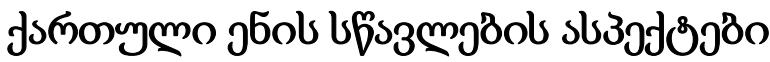

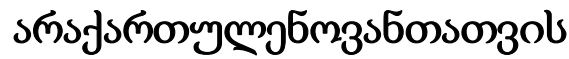

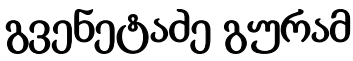

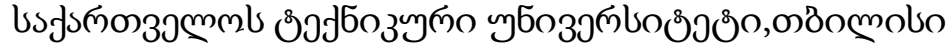 \\ https://doi.org/10.52340/idw.2021.536
}

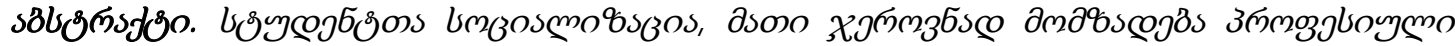

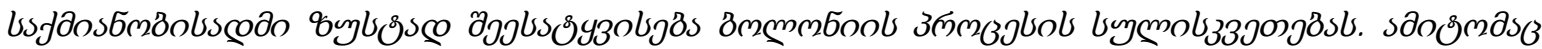

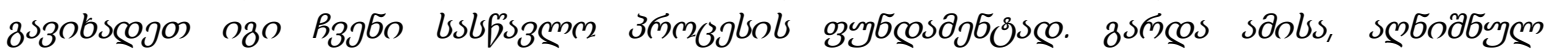

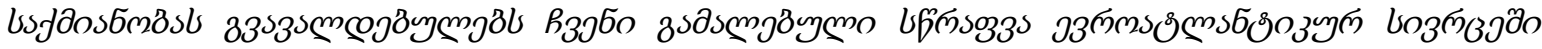

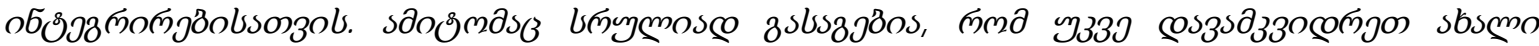

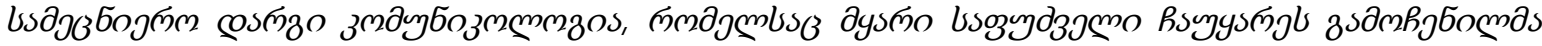

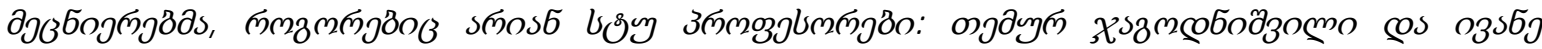

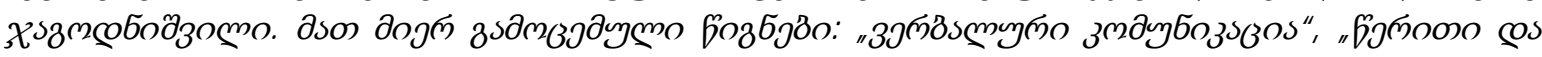

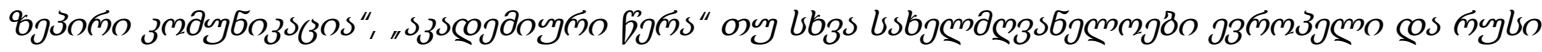

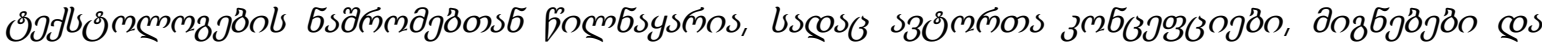

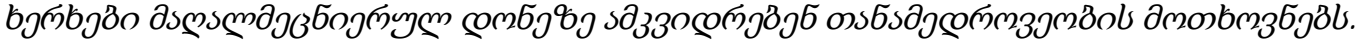

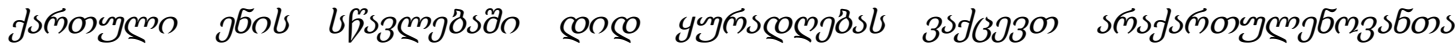

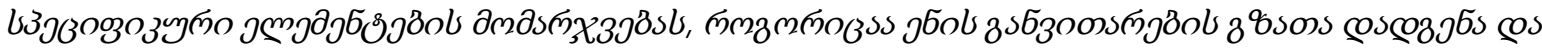

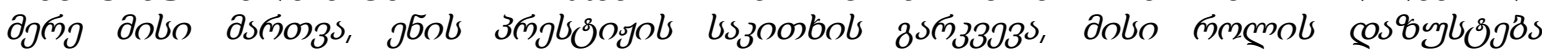

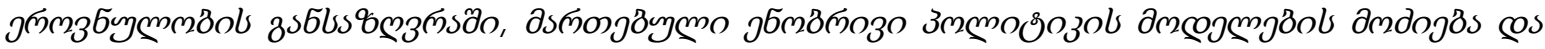
cosaz3ocomg8s.
\end{abstract}

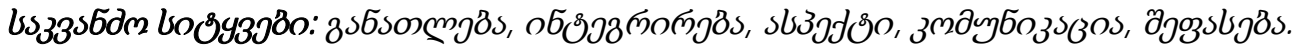

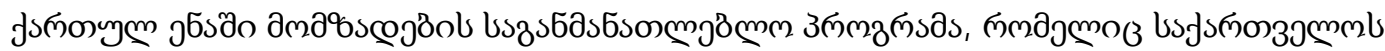

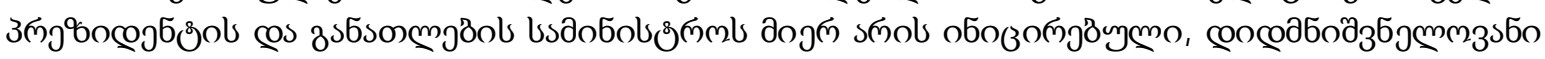

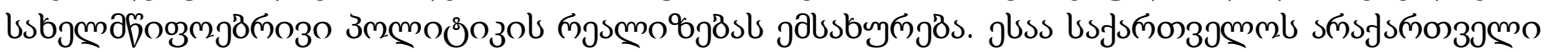

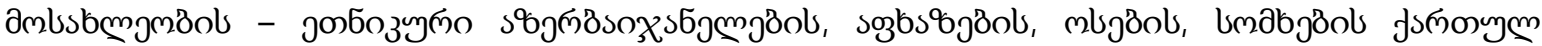

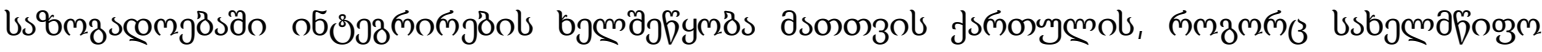

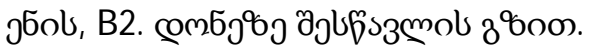

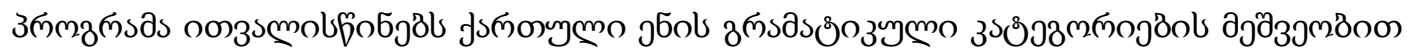

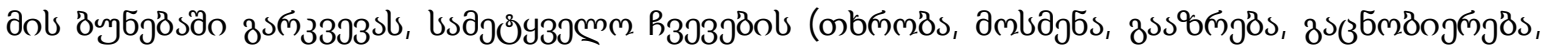

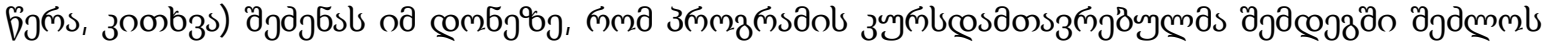
usfsলn

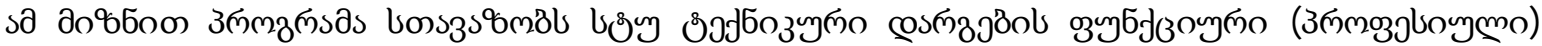

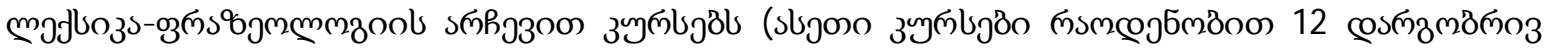

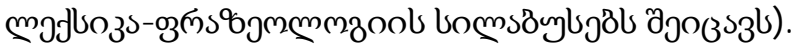

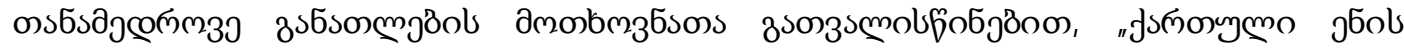

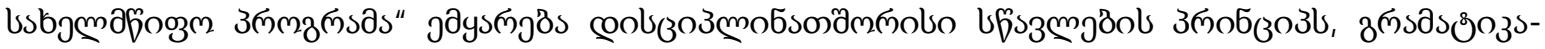

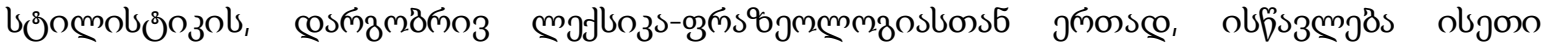

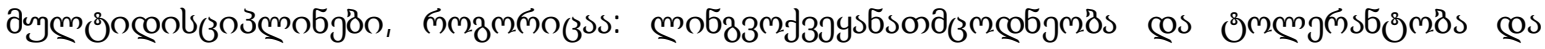

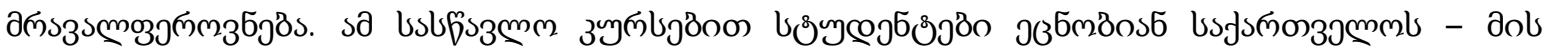

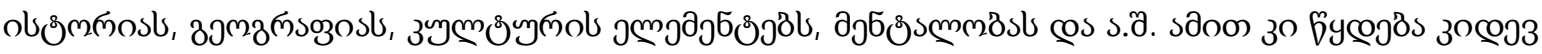




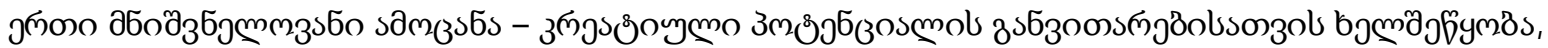

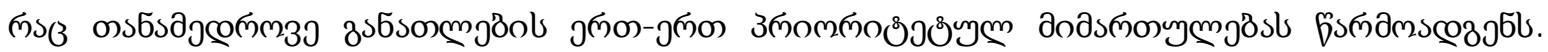

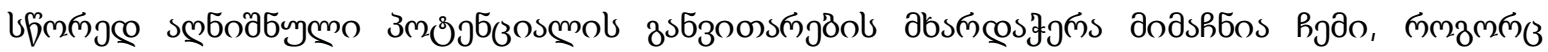

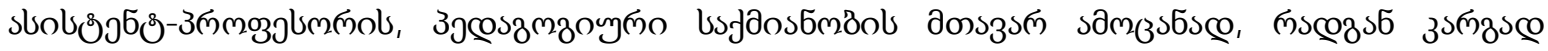

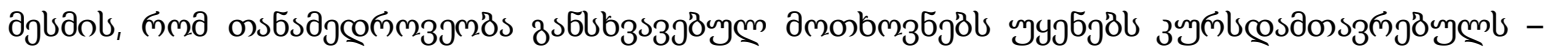

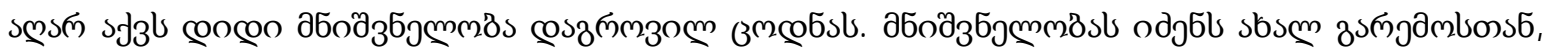

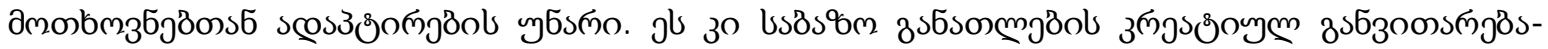

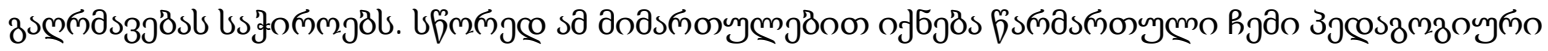
usjДosбmßs.

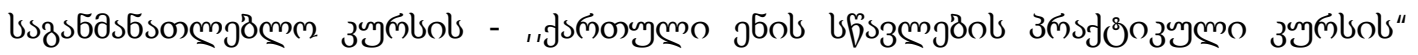

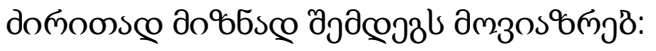

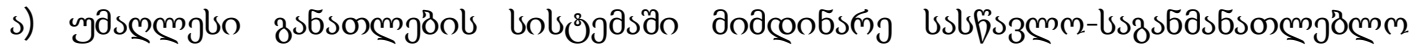

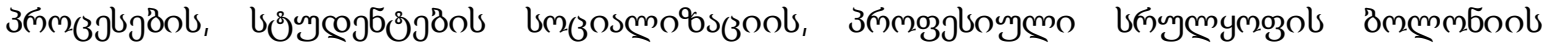

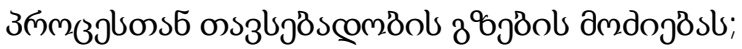

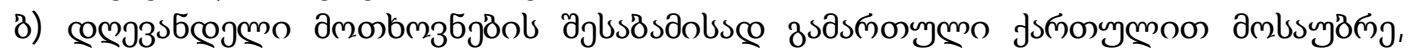

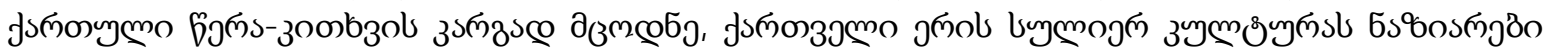

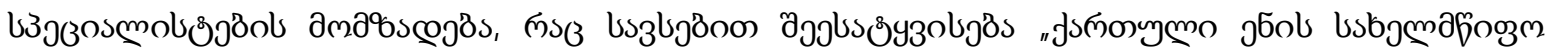

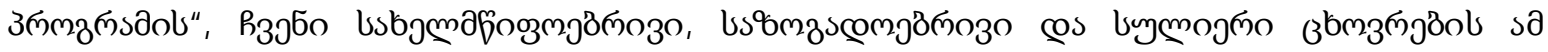

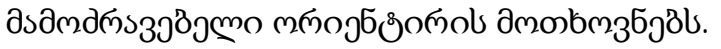

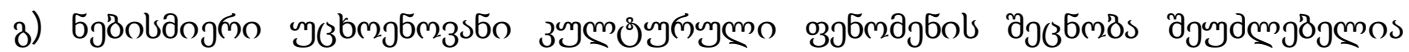

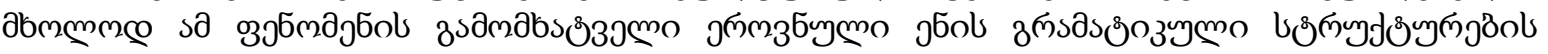

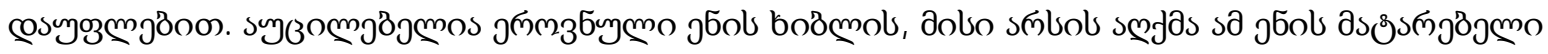

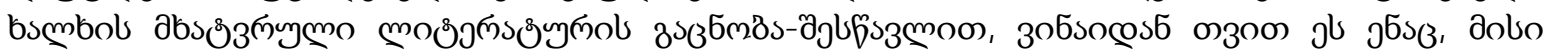

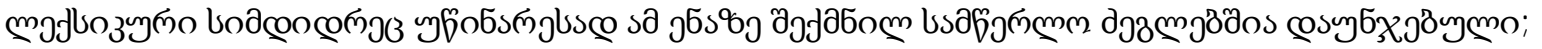

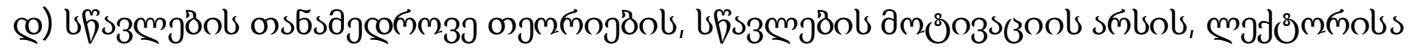

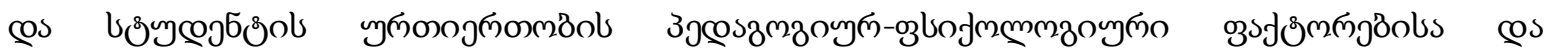

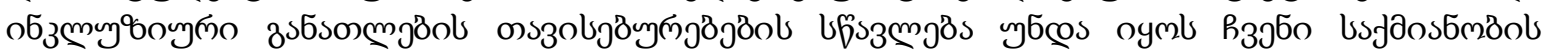

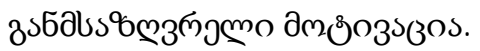

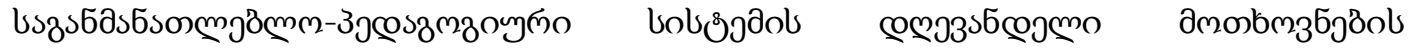

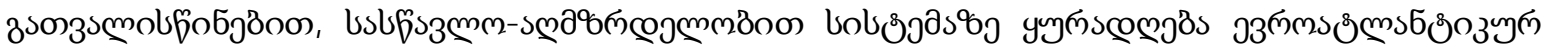

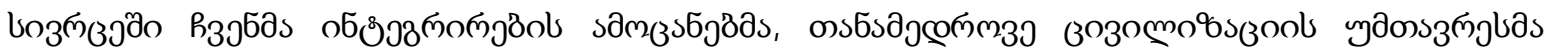

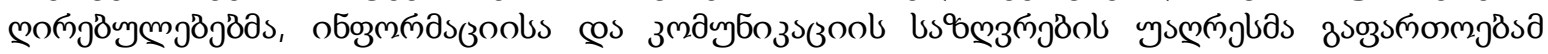

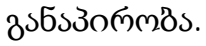

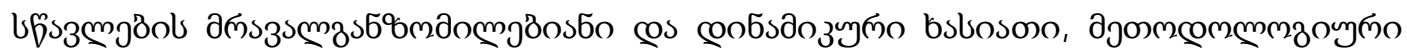

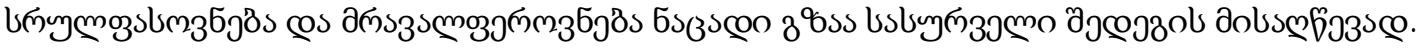

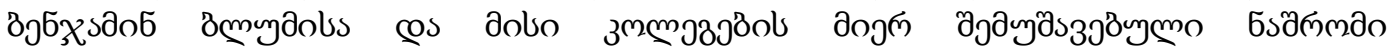

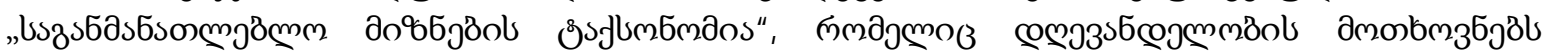

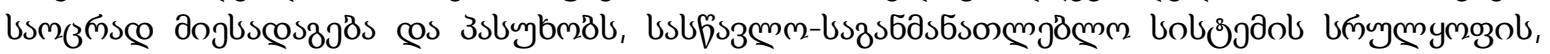

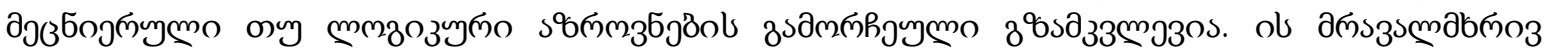

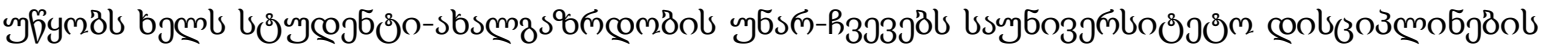

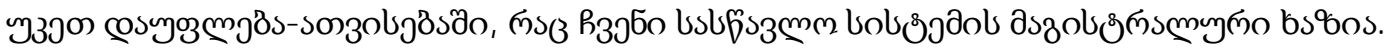

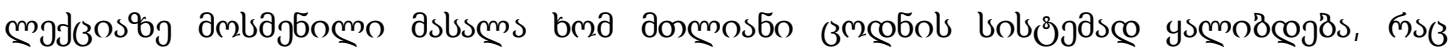

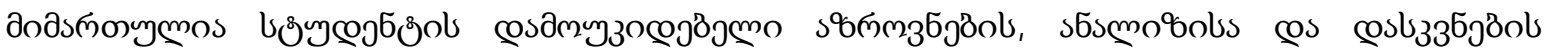

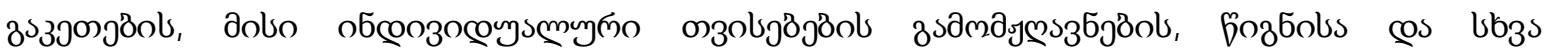

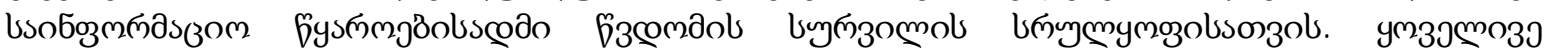

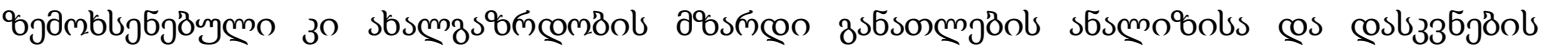

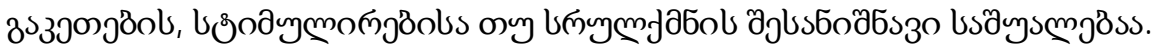

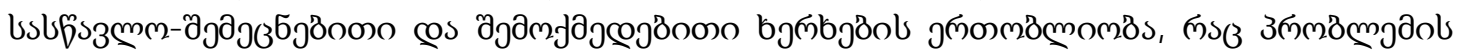

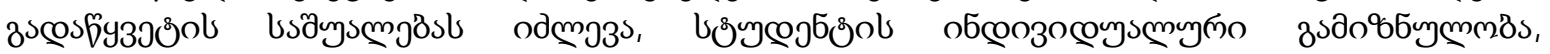

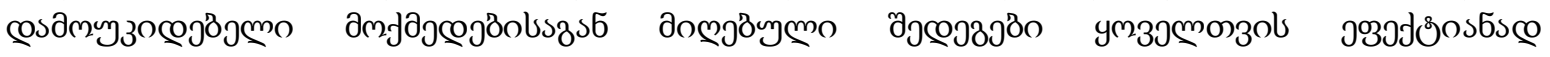




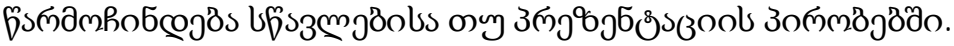

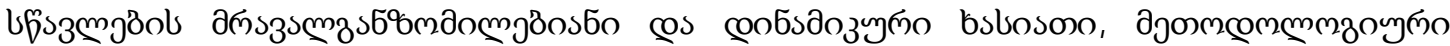

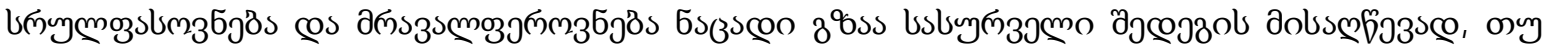

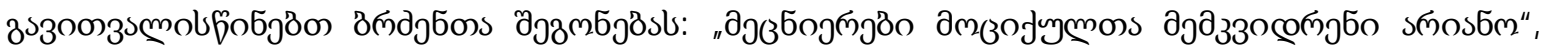

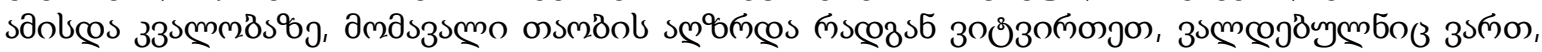

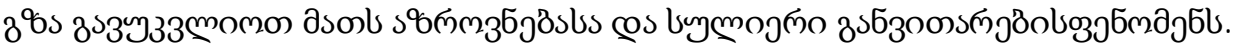

zulssonzs molfoб

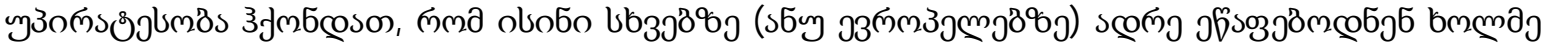

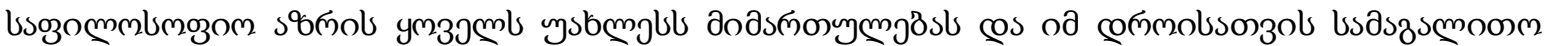

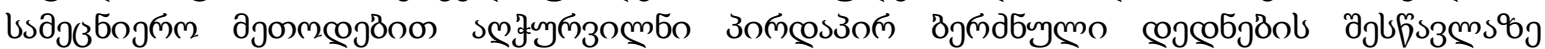

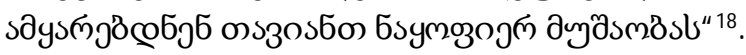

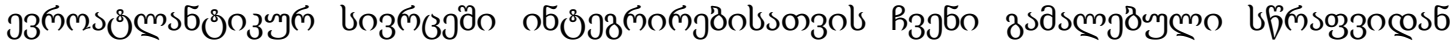

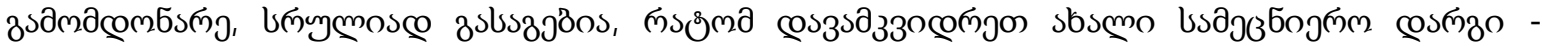

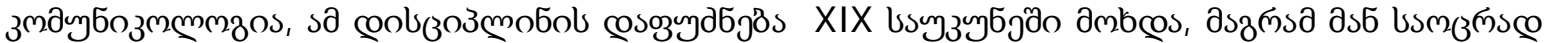

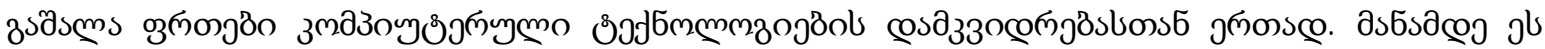

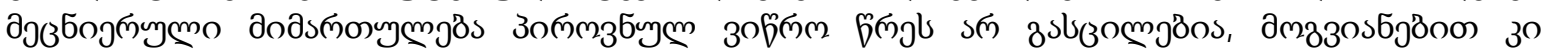

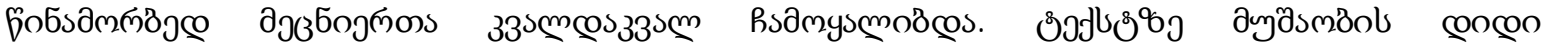

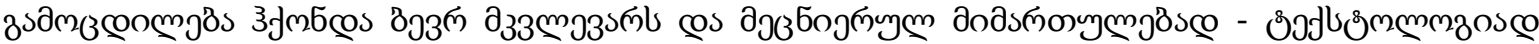

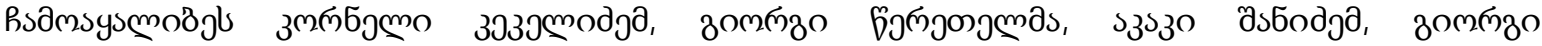

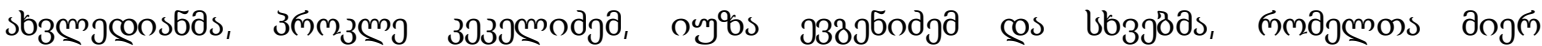

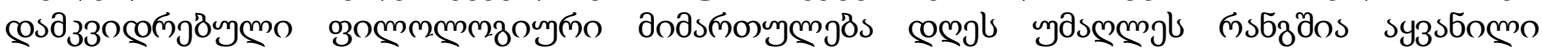

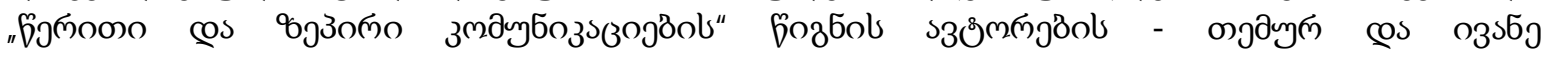

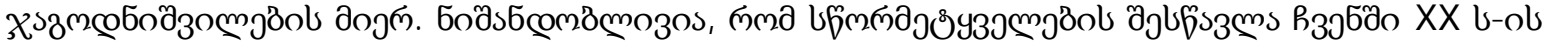

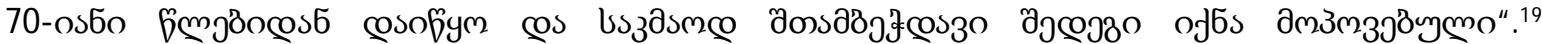

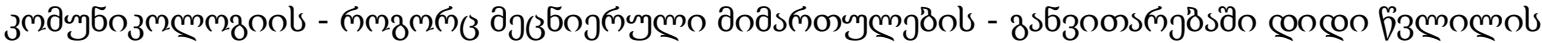

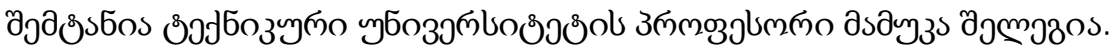

తీวلfloీ

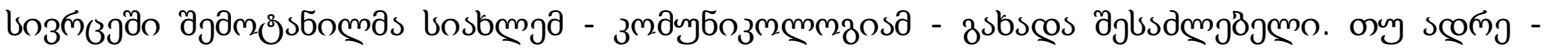

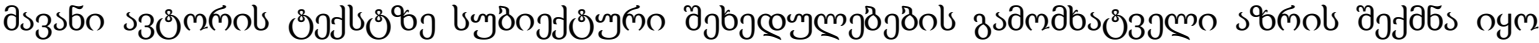

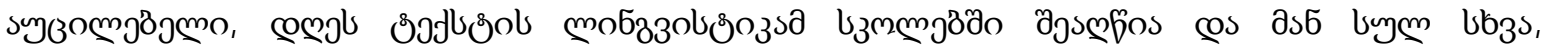

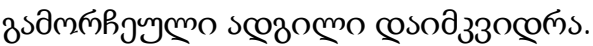

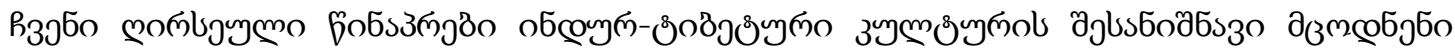

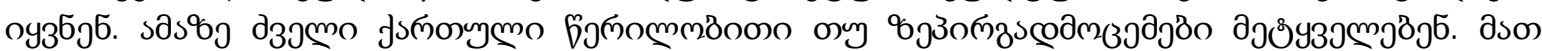

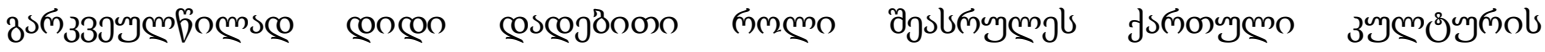

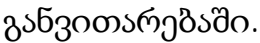

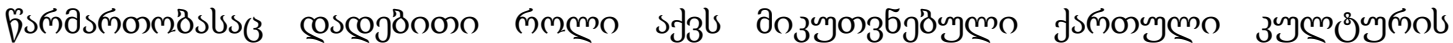

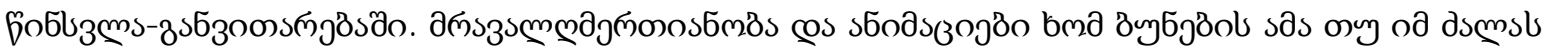

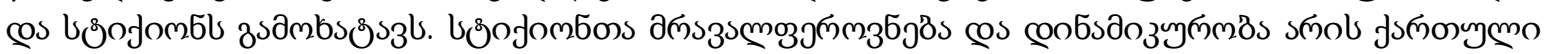

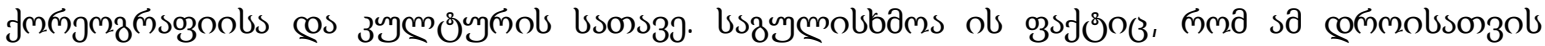

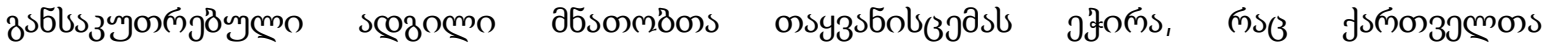

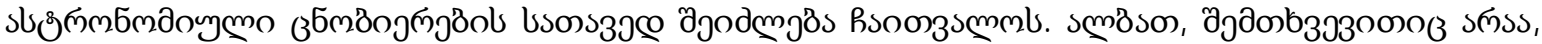

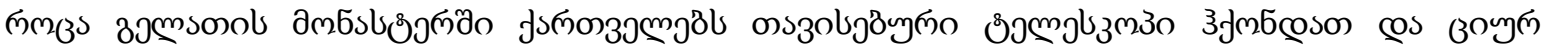

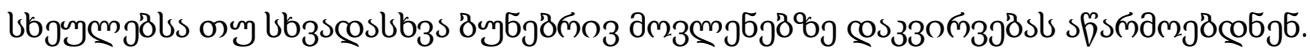

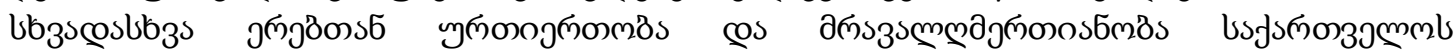

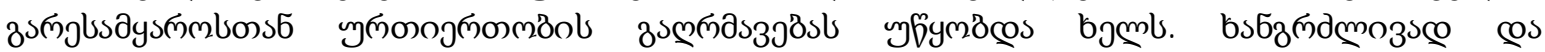

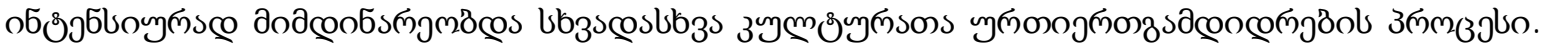

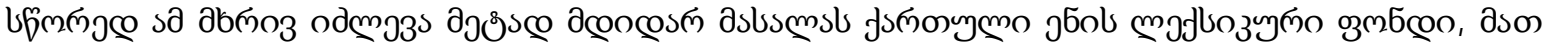

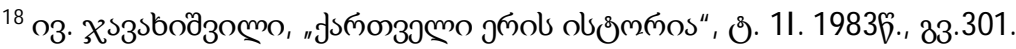

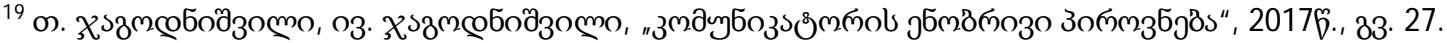




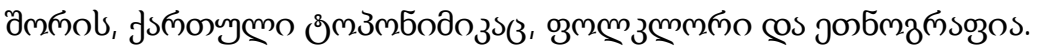

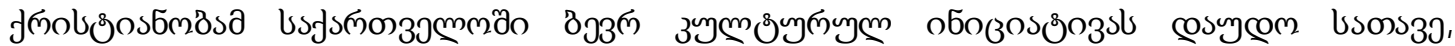

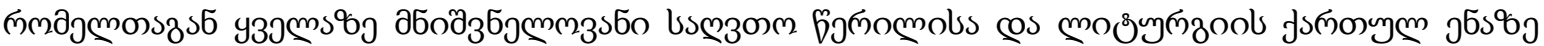

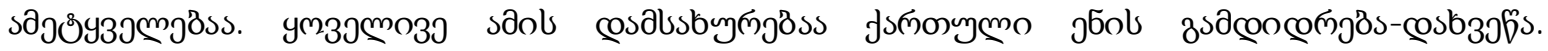

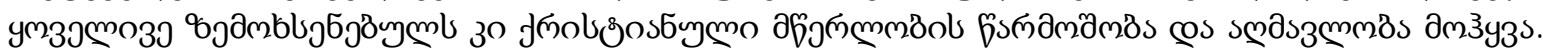

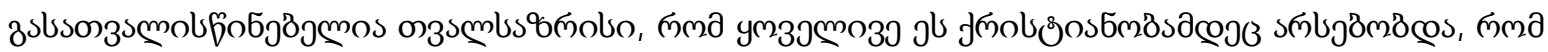

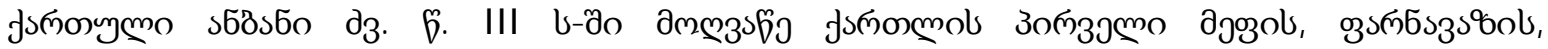

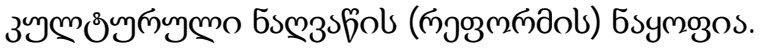

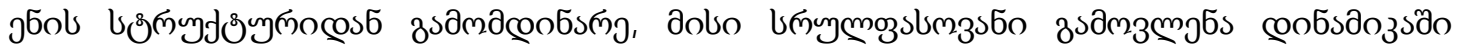

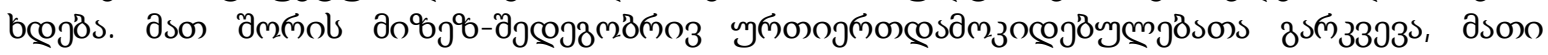

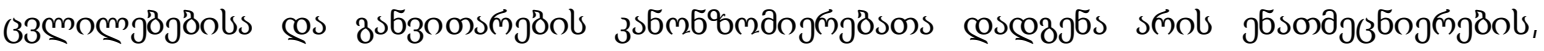

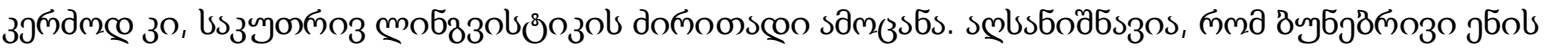

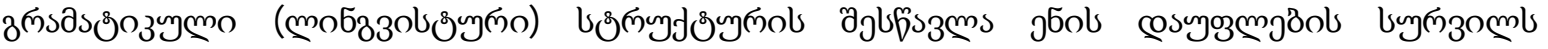

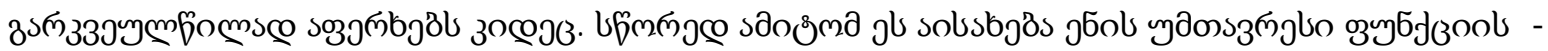

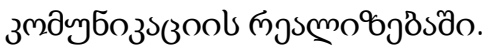

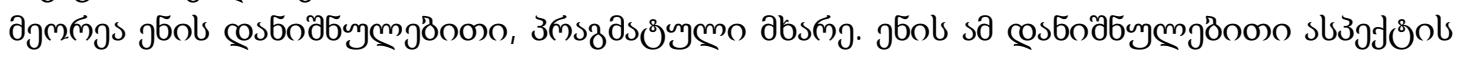

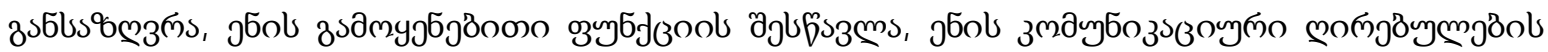

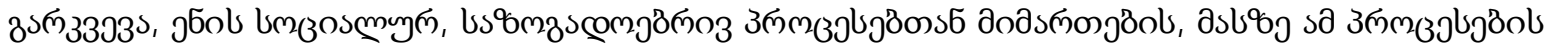

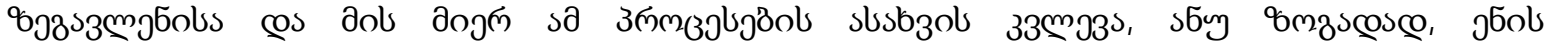

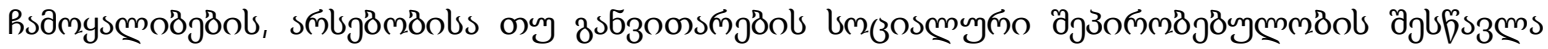

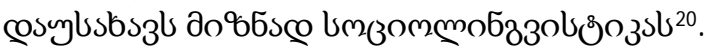

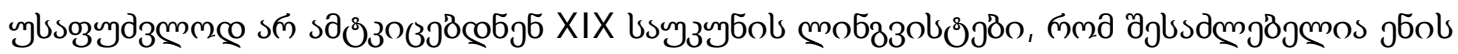

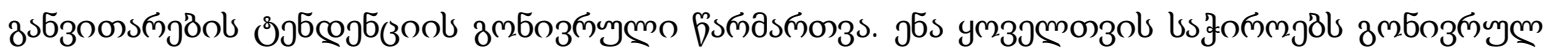

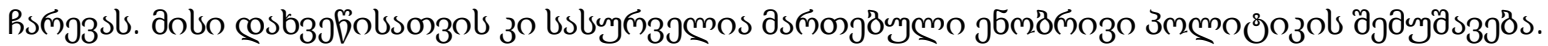

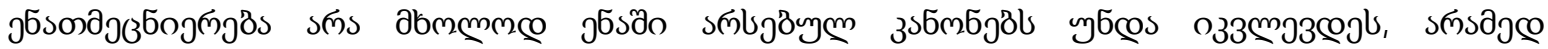

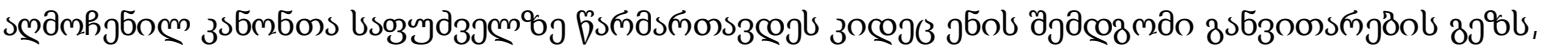

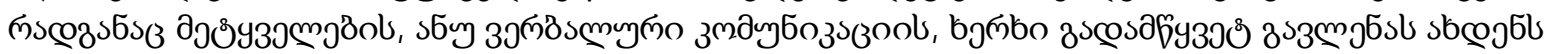

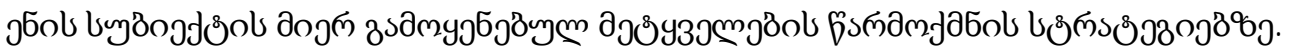

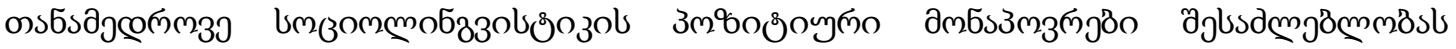

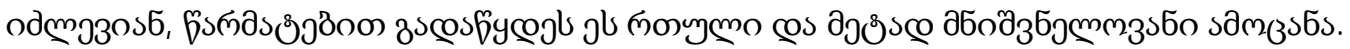

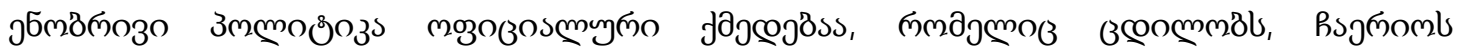

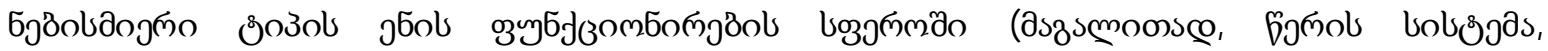

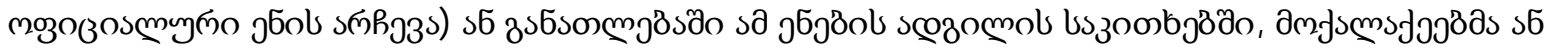

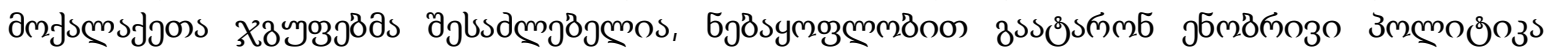

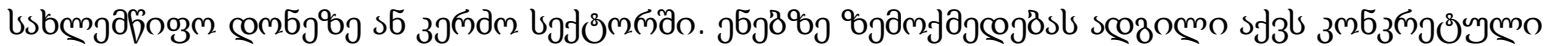

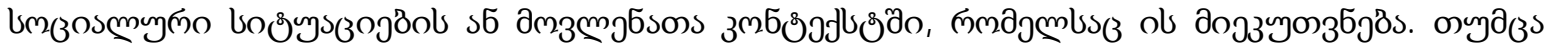

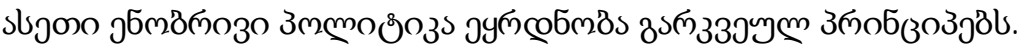

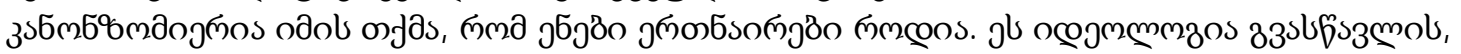

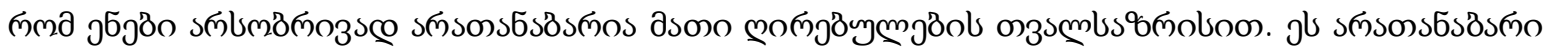

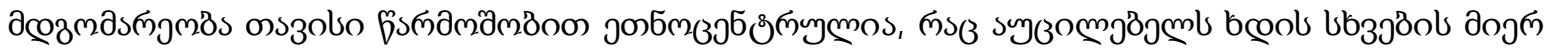

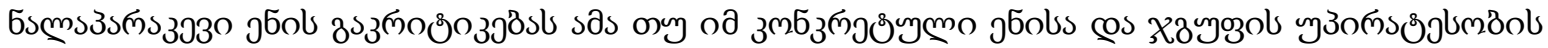

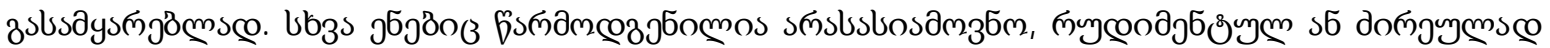

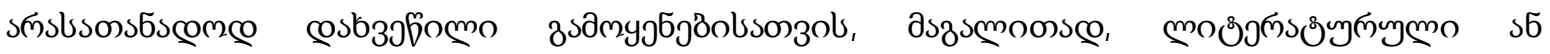

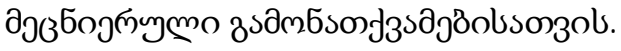

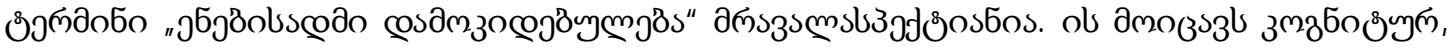

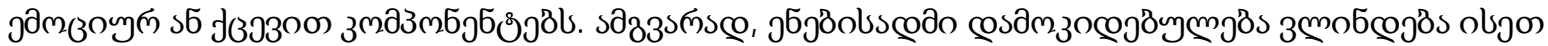

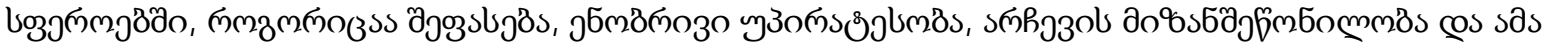

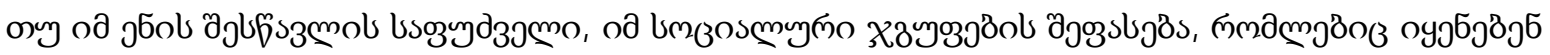

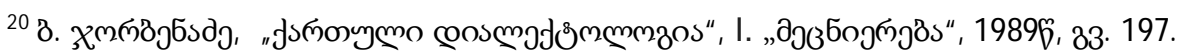




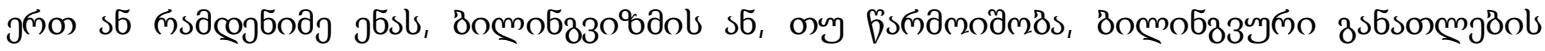

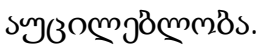

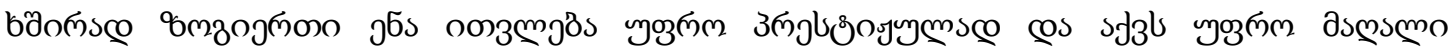

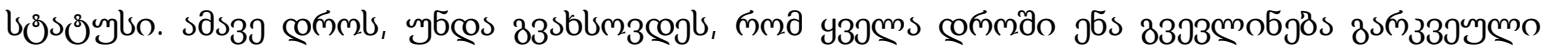

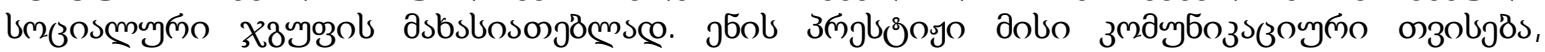

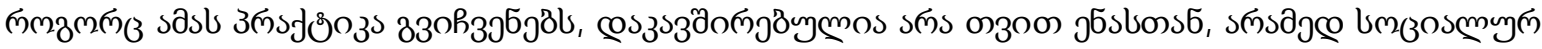

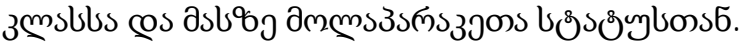

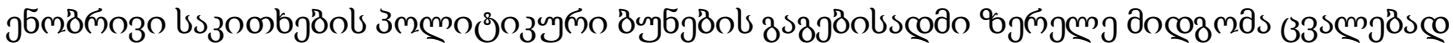

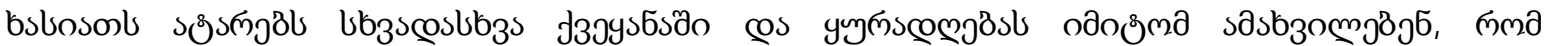

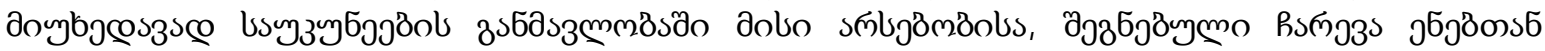

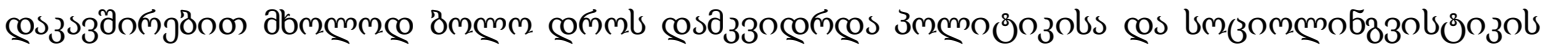

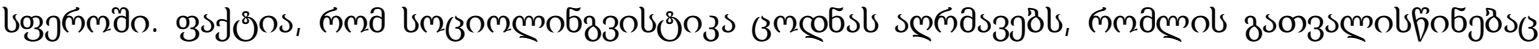

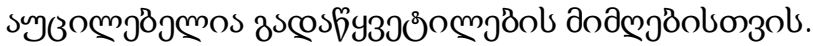

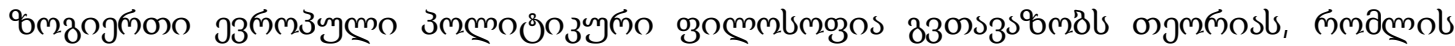

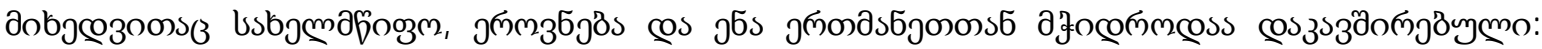

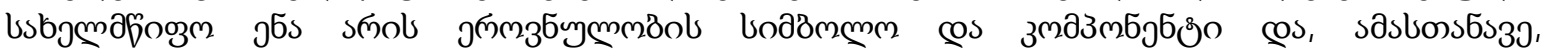

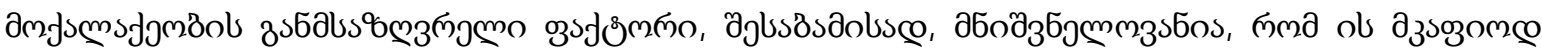

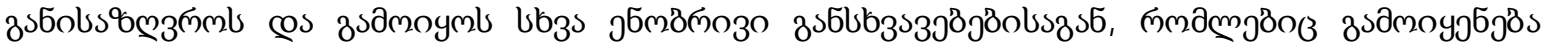

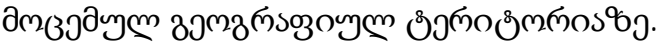

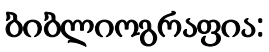

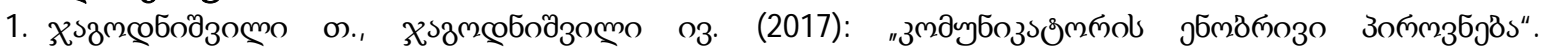

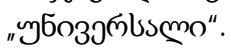

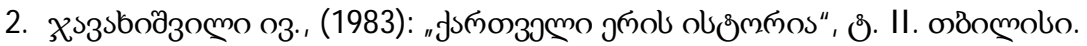

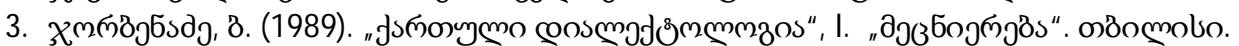

\section{Aspects of Teaching the Georgian Language to Non-Georgian Speakers}

Gvenetadze Guram

Georgian Technical University,Tbilisi

\begin{abstract}
Socialization of students, their proper preparation for professional activities exactly corresponds to the spirit of the Bologna Process. That is why it became the basis for our learning process. Besides, our frenetic aspiration to integrate into the Euro-Atlantic space obliges us to follow the mentioned activity. Therefore, it is absolutely clear that we have already established a new scientific field - communicology. The eminent scholars, such as professors of Georgian Technical University Temur Jagodnishvili and Ivane Jagodnishvili laid the firm foundation for the development of the mentioned field.

The books published by them: "Oral Communication," "Written and Oral Communication," "Academic Writing" or other textbooks are of the same level as the works of European and Russian textual critics, where the authors' concepts, findings, and methods establish the requirements of the modernity at a high scientific level. In the process of teaching the Georgian language, we pay special attention to the use of specific elements of non-Georgian speakers; for instance, determining the ways of language development and its management, clarifying the issue of language prestige, specifying its role in determining nationality, finding and establishing valid language policy models.
\end{abstract}

Keywords: Education, Integration, Aspect, Communication, Rate. 